\title{
Drug repositioning can accelerate discovery of pharmacological chaperones
}

\author{
Bruno Hay Mele ${ }^{1}$, Valentina Citro ${ }^{2}$, Giuseppina Andreotti ${ }^{3^{*}}$ and Maria Vittoria Cubellis ${ }^{2^{*}}$
}

\begin{abstract}
A promising strategy for the treatment of genetic diseases, pharmacological chaperone therapy, has been proposed recently. It exploits small molecules which can be administered orally, reach difficult tissues such as the brain and have low cost. This strategy has a vast field of application. In order to make drug development as fast as possible, it is important to exploit drug repositioning. We evaluated the impact and limitations of this approach for rare diseases and we provide a shortcut in finding drugs for off-target usage.
\end{abstract}

Keyword: Pharmacological chaperone, Drug repositioning

\section{Correspondence/Findings}

A large share of mutations associated to human diseases causes the destabilization of specific proteins. The activity of unstable proteins can be rescued by small molecules that act as pharmacological chaperones (PC). Usually PC are inhibitors or antagonists of their targets used at a very low concentration, but other types of molecules such as activators or allosteric ligands, which do not reduce activity, would be more appropriate [1-3]. There is a limit in this approach because not all the genotypes of a given disease are eligible for therapy with $\mathrm{PC}$ and only in some cases is it possible to predict the responsiveness of specific mutations [4].

Drug repositioning could accelerate the discovery of PC. The first successful case is provided by imino-sugars that interfere with $\mathrm{N}$-glycosylation in cells infected by enveloped viruses, deoxynojirimcin and its derivatives [5]. Clinical trials for the treatment of HIV with deoxynojirimcines were unsuccessful, because the antiviral concentration required could not be achieved in humans. However the same imino-sugars could be used as PC at low concentration for a different target, glucosylceramidase (Uniprot: P04062), to treat Gaucher disease (MIM: 230800) [6] and lysosomal alpha-glucosidase (Uniprot: P10253), to treat Pompe disease (MIM: 232300) [7,8]. The usage of imino-

\footnotetext{
*Correspondence: giuseppina.andreotti@icb.cnr.it; cubellis@unina.it

${ }^{3}$ Istituto di Chimica Biomolecolare -CNR, Pozzuoli, Italy

${ }^{2}$ Department of Biology, University Federico II, Naples, Italy

Full list of author information is available at the end of the article
}

sugars was then extended to other lysosomal glycosidases to cure some storage disorders.

Drug repositioning should be run systematically for the discovery of PC. To support our proposal we gathered all the proteins that are associated to rare diseases, i.e. the entries that have a link to Orphanet [9] in Uniprot (Orphan_proteins). For 608 entries out of a total of 3289 Orphan_proteins we found a link to DrugBank, a database including FDA-approved small molecules, experimental and nutraceuticals drugs [10]. DrugBank annotates each record with the known pharmacological protein target, but also with other proteins that are activated or inhibited by the drug. In the vast majority of cases, links between Orphan_proteins and drugs only indicate relations documented in the literature, but do not implicate a recognized pharmacological action of the drug on the target. The histogram in Figure 1 shows that several Orphan_proteins interact with one or more approved small molecules and the list is provided in Additional file 1 . Since our aim is to support the usefulness of repositioning, we excluded biotech drugs because some of them have already been approved for enzyme replacement therapy of rare diseases. We also excluded cytochromes, which contribute to the metabolism of many drugs. Small chemicals that interact with Orphan_proteins are excellent starting points to develop PC. A proof of concept is represented by a paper which 


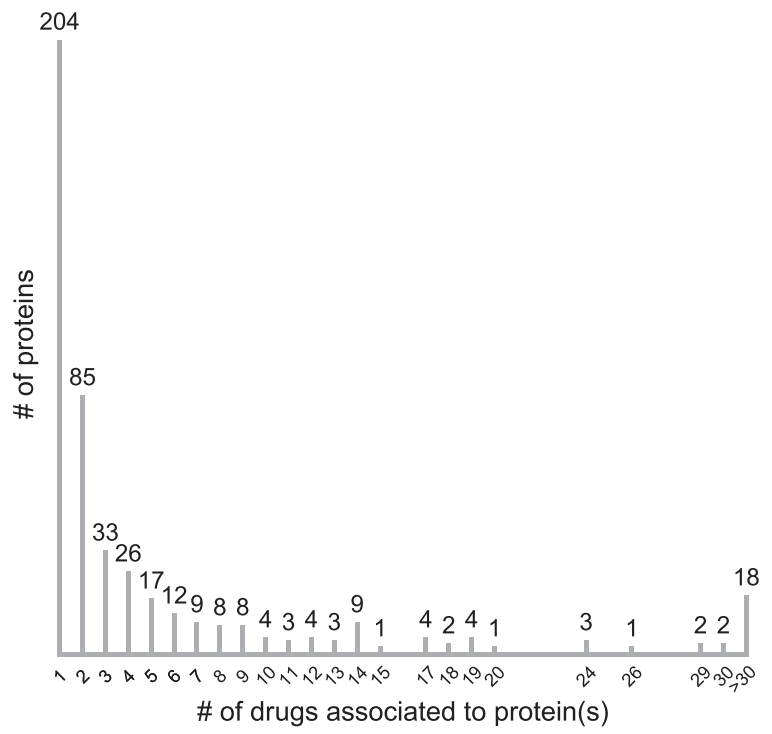

Figure 1 Orphan_Protein distribution per drug. Proteins associated to rare diseases are ordered by a number of interacting small molecule FDA-approved drugs. appeared in 2015 [11] where a screening of 3200 known drugs from commercial compound libraries led to the identification of Ibuprofen as a corrector of the transmembrane conductance regulator (CFTR) (Uniprot: P13569). Ibuprofen has a pharmacological action on Prostaglandin synthase 1 and 2 (Uniprot: P35354, P23219), but besides this action, DrugBank reports the inhibition of CFTR based on a paper published in 1998 [12].

In addition, we found several other cases in which small approved drugs were successfully repositioned as PC for rare diseases: doxorubicin, an anti-neoplastic anthracycline, for Cystic fibrosis (MIM: 219700) [13], Diltiazem, an antihypertensive, for Gaucher disease (MIM: 230800) [14], Ambroxol, a mucolytic agent, for Gaucher and for Fabry disease (MIM: 301500) [15,16], Acetylcysteine, another mucolytic agent, for Pompe disease (MIM: 232300) [17], Pyrimethamine, an anti-parasitic compound, for GM2 gangliosidosis (MIM: 272800) [18], carbamazepine, a dibenzazepine, for Hyperinsulinemic Hypoglycemia (MIM: 256450) [19] and Salicylate for Pendred Syndrome (MIM: 274600) [20].

In these cases, however, the link between the drug and the Orphan_protein, could not be found in DrugBank. This absence of annotation shows how difficult it is to mine the literature and we admit that also our list of approved drugs tested as PC may be incomplete. The development of drugs for rare diseases would benefit from a mechanism that favours the deposition of data concerning the interaction of small molecules and proteins into databanks.

\section{Additional file}

Additional file 1: Orphan_Proteins associated to approved small molecules are listed. The column headings are: Entry, Uniprot ID; Entry Name, Uniprot entry name; Status, reviewed if SWISS-Prot entry; Protein names, protein full name; Gene names, Names of each gene associated to the protein; DrugBank cross-reference, List of drugs associated (by DrugBankID); Orphanet cross-reference: List of orphan diseases (by OrphanID) associated to the protein.

\section{Abbreviations}

PC: Pharmacological chaperone; CFTR: Cystic fibrosis transmembrane conductance regulator.

\section{Competing interests}

MVC was a consultant for Shire HGT.

\section{Authors' contributions}

GA and MVC designed the study and wrote the paper. BHM and VC carried out data-mining. All authors read and approved the final manuscript.

\section{Acknowledgements}

The financial support of Telethon - Italy (Grant no. GGP12108) and PON Ricerca e Competitività 2007-2013 (02_00619_3461281) are gratefully acknowledged.

\section{Author details}

'Department of Agricultural and Food Sciences, University Federico II, Naples, Italy. ${ }^{2}$ Department of Biology, University Federico II, Naples, Italy. ${ }^{3}$ Istituto di Chimica Biomolecolare -CNR, Pozzuoli, Italy.

Received: 30 March 2015 Accepted: 23 April 2015

Published online: 07 May 2015

\section{References}

1. Goldin E, Zheng W, Motabar O, Southall N, Choi JH, Marugan J, et al. High throughput screening for small molecule therapy for Gaucher disease using patient tissue as the source of mutant glucocerebrosidase. PLoS One. 2012;7(1):e29861.

2. Newton CL, Whay AM, McArdle CA, Zhang M, van Koppen CJ, van de Lagemaat $R$, et al. Rescue of expression and signaling of human luteinizing hormone $\mathrm{G}$ protein-coupled receptor mutants with an allosterically binding small-molecule agonist. Proc Natl Acad Sci U S A. 2011;108(17):7172-6.

3. Andreotti G, Cabeza De Vaca I, Poziello A, Monti MC, Guallar V, Cubellis MV. Conformational response to ligand binding in Phosphomannomutase2: insights into inborn glycosylation disorder. J Biol Chem. 2014;289(50):34900-10.

4. Andreotti G, Guarracino MR, Cammisa M, Correra A, Cubellis MV. Prediction of the responsiveness to pharmacological chaperones: lysosomal human alpha-galactosidase, a case of study. Orphanet J Rare Dis. 2010;5:36.

5. Tierney M, Pottage J, Kessler H, Fischl M, Richman D, Merigan T, et al. The tolerability and pharmacokinetics of N-butyl-deoxynojirimycin in patients with advanced HIV disease (ACTG 100). The AIDS Clinical Trials Group (ACTG) of the National Institute of Allergy and Infectious Diseases. J Acquir Immune Defic Syndr Hum Retrovirol. 1995;10(5):549-53.

6. Sawkar AR, Cheng WC, Beutler E, Wong CH, Balch WE, Kelly JW. Chemical chaperones increase the cellular activity of N370S beta -glucosidase: a therapeutic strategy for Gaucher disease. Proc Natl Acad Sci U S A. 2002;99(24):15428-33.

7. Okumiya T, Kroos MA, Vliet LV, Takeuchi H, Van der Ploeg AT, Reuser AJ. Chemical chaperones improve transport and enhance stability of mutant alpha-glucosidases in glycogen storage disease type II. Mol Genet Metab. 2007;90(1):49-57.

8. Parenti G, Zuppaldi A, Gabriela Pittis M, Rosaria Tuzzi M, Annunziata I, Meroni G, et al. Pharmacological enhancement of mutated alphaglucosidase activity in fibroblasts from patients with Pompe disease. Mol Ther. 2007;15(3):508-14.

9. Orphanet. Orphanet. 2015. http://www.orpha.net/consor/cgi-bin/index.php

10. Law V, Knox C, Djoumbou Y, Jewison T, Guo AC, Liu Y, et al. DrugBank 4.0: shedding new light on drug metabolism. Nucleic Acids Res. 2014;42(Database issue):D1091-7. 
11. Carlile GW, Robert R, Goepp J, Matthes E, Liao J, Kus B, et al. Ibuprofen rescues mutant cystic fibrosis transmembrane conductance regulator trafficking. J Cyst Fibros. 2015;14(1):16-25.

12. Devor DC, Schultz BD. Ibuprofen inhibits cystic fibrosis transmembrane conductance regulator-mediated Cl- secretion. J Clin Invest. 1998;102(4):679-87.

13. Maitra R, Hamilton JW. Altered biogenesis of deltaF508-CFTR following treatment with doxorubicin. Cell Physiol Biochem. 2007;20(5):465-72.

14. Rigat B, Mahuran D. Diltiazem, a L-type Ca (2+) channel blocker, also acts as a pharmacological chaperone in Gaucher patient cells. Mol Genet Metab. 2009;96(4):225-32.

15. Bendikov-Bar I, Maor G, Filocamo M, Horowitz M. Ambroxol as a pharmacological chaperone for mutant glucocerebrosidase. Blood Cells Mol Dis. 2013;50(2):141-5

16. Lukas J, Pockrandt AM, Seemann S, Sharif M, Runge F, Pohlers S, et al. Enzyme enhancers for the treatment of fabry and pompe disease. Mol Ther. 2015;23(3):456-64.

17. Porto C, Ferrara MC, Meli M, Acampora E, Avolio V, Rosa M, et al, Pharmacological enhancement of alpha-glucosidase by the allosteric chaperone N-acetylcysteine. Mol Ther. 2012;20(12):2201-11.

18. Maegawa GH, Tropak M, Buttner J, Stockley T, Kok F, Clarke JT, et al. Pyrimethamine as a potential pharmacological chaperone for late-onset forms of GM2 gangliosidosis. J Biol Chem. 2007;282(12):9150-61.

19. Martin GM, Chen PC, Devaraneni P, Shyng SL. Pharmacological rescue of trafficking-impaired ATP-sensitive potassium channels. Front Physiol. 2013;4:386.

20. Ishihara K, Okuyama S, Kumano S, lida K, Hamana H, Murakoshi M, et al. Salicylate restores transport function and anion exchanger activity of missense pendrin mutations. Hear Res. 2010;270(1-2):110-8.

\section{Submit your next manuscript to BioMed Central and take full advantage of:}

- Convenient online submission

- Thorough peer review

- No space constraints or color figure charges

- Immediate publication on acceptance

- Inclusion in PubMed, CAS, Scopus and Google Scholar

- Research which is freely available for redistribution 